\title{
DOS METONIMIAS DE NERUDA Y PARRA: EL BOLERO Y LA CUECA
}

\author{
Mario Rodríguez \\ Universidad de Concepción \\ mariorod@udec.cl
}

RESUMEN / ABSTRACT

Bolero y cueca se proponen como metonimias de una prosodia y sintaxis poética empleada por Neruda en Veinte poemas de amor y una canción desesperada y por Parra en La cueca larga y Artefactos. Trabajo fundamentalmente con el ritmo y la melodía de los versos superando la división entre lengua y música.

PALABRAS ClAVE: bolero, cueca, ritmo, melodía, metonimia.

"La cueca" and "el bolero" are musical forms proposed as metonymies of a poetic prosody and syntax in Neruda's Veinte poemas de amor y una canción desesperada, and in Parra's La cueca larga and Artefactos. This work focuses mainly on the rhythmic and melodic substance of the verses, thus surpassing a division between language and music.

KEY WORDS: Bolero, cueca, rhythm, melody, metonymy.

Haciendo un día la prueba de leer los Veinte poemas de amor y una canción desesperada como si los estuviese escuchando y no leyendo, capté un feeling que me hacía recordar nítidamente al bolero.

En este "feeling" la dramatización de los sentimientos del sujeto lírico estaba pensada para que el "lector-oyente" no solo leyera y/o escuchara, sino sintiera el mismo tipo de sentimientos del poeta.

Una cita de Edwards aclara, tal vez, la transferencia: 
A la vez hablaba con satisfacción (Neruda), con algo de ingenuidad, de las parejas que se le acercaban, en Santiago, en el Sur de Chile, en plazas de provincias de las ciudades más remotas de América y le confesaban agradecidas, que la lectura de los Veinte poemas había dominado en sus primeros encuentros y había contribuido a decidir su destino. El "Poema 20" había sido como el himno nacional de muchos amores sudamericanos (La otra casa 86).

El devenir de una subjetividad individual a una colectiva podría explicarse porque los enamorados debían sentir que el poeta dejaba el alma en cada poema y esta alma era como la suya. En otros términos, ya definitivamente teóricos, Neruda fue capaz de hacer un agenciamiento con el imaginario amoroso latinoamericano. El autor de los Veinte poemas logró diligenciar una relación cercana y potente con las formas de amar de la sociedad chilena y latinoamericana, a tal punto, que, como dice Edwards, el "Poema 20 " se transformó en el "himno nacional", en un canto que interpretaba los sentimientos colectivos amorosos del pueblo. En dicha línea, los Veinte poemas siguen siendo el texto más popular de Neruda. No hay ningún otro libro que lo iguale.

No es solo el "feeling" el que acerca el texto nerudiano al bolero, que como establece uno de sus estudiosos, es una de las formas artísticas más genuinas producidas por la cultura latinoamericana, sino también el ritmo prosódico lento de los versos que recuerden la lentitud melódica del bolero en su compás de $4 / 4$. Y en este punto me atrevo a incorporar el baile, parte esencial del bolero, reconstruyendo una metáfora con los movimientos de la pareja. Aplicables al movimiento del poema "La pareja", dentro de los cuatro tiempos del bolero, permanece enlazada en el primer tiempo y solo se mueve a partir del segundo dando un paso rápido. Metafóricamente, el "Poema 1"1, por ejemplo, tiene un comienzo en que predomina la inmovilidad en la que se va a asentar todo el poema: "Cuerpo de mujer, blancas colinas, muslos blancos / te pareces al mundo en su actitud de entrega" (11). Predomina la contemplación. Solo en el segundo compás se empieza a "mover" el texto: "mi cuerpo de labriego salvaje te socava" (11). El siguiente "paso" es también muy rápido en la acción: "y hace saltar al hijo del fondo de la tierra" (11). El cuarto y último compás retoma la inmovilidad del primero: "Fui solo como un túnel” (11), completando así el ritmo lento del bolero. 
Proyectando esta composición de 4/4 a la totalidad del volumen Veinte poemas, podría argüirse que la primera fase léxica, prosódica y sintáctica del texto se organiza en torno al cuerpo de la mujer como un centro estabilizante del imaginario erótico. Materialidad, sensualidad, blancura son los componentes de la corporalidad telúrica de la mujer. La segunda fase es el progresivo afantasamiento de la amada: "Sólo guardas tinieblas, hembra distante mía" ("Poema 7"21). De la integridad proporcionada por la contemplación, hemos pasado al siguiente paso del baile, el movimiento desintegrador. El tercer compás es el de la recomposición que proporciona el arte: "puedo escribir los versos..." ("Poema 20" 47). La contemplación, el fantasma y la desintegración resultan ser los materiales con los cuales se construye la poética y la estética del poeta. Es la última forma de enlazamiento de la pareja, en otros términos.

Ella se deshace en el paso final representado por "La canción desesperada": "Es la hora de partir, oh abandonado" (53).

Enlazamiento de la pareja y desenlazamiento en el baile de compases lentos representa metafóricamente el movimiento textual de los Veinte poemas. Ritmo, melodía y texto que producen un "feeling" con las anónimas parejas de provincia.

La genialidad de Neruda consistió en hacer un agenciamiento con el imaginario amoroso latinoamericano. Escribir unos versos en los que se sentían representados vastos sectores sociales de nuestra América. A tal punto, que podían apropiarse de algunos de esos versos para sentirlos como suyos.

En esta apropiación reside el punto de encuentro con el bolero. Neruda en los Veinte poemas y los boleristas calaron justo en el corazón y el alma enamorada del pueblo. De allí inventaron una forma de amor que la colectividad reconoció como suya. "Escribir es inventar un pueblo que falta", afirma Deleuze (10).

La prosodia lenta que embarga el texto de Neruda encuentra su analogía en los compases $4 / 4$ del bolero. "Puedo escribir los versos más tristes esta noche", parece tan imborrable como el "solamente una vez se ama en la vida". Ambas afinaciones están encarnadas en todos nosotros, ¿para siempre?

Enfoco ahora un agenciamiento totalmente distinto: el efectuado por Nicanor Parra a partir de La cueca larga (1966) que rompe con la poesía "mirando hacia París" de Poemas y antipoemas. Parra, el "antineruda", hace un contacto estupendo con un ritornelo popular y folclórico que a su vez está en relación con un inmenso canto del pueblo chileno. Este canto se vincula a lo natal, a lo originario y se territorializa en un Chile profundo de la zona central. 
Escribe Jorge Edwards:

La revelación de Martín Fierro llevó a Parra a encontrarse con el Chile campesino, provinciano, profundo, de su infancia y adolescencia. Creo ahora que fue un descubrimiento común hecho con Violeta Parra, su hermana de sangre y del alma. En alguna medida fui testigo de ese proceso. Violeta había comenzado como cantante popular, en el sentido más bien comercial del término, hasta que decidió buscar en el campo, entre viejos cantores y cantoras, las raíces de lo que se llamaba por tierras de Chillán adentro, hacia la cordillera, canciones a lo humano y lo divino, profano y religiosas. Así encontró formas musicales originales, que después llegaron a todas partes, en esta búsqueda de un pasado remoto, de esta especie de Edad Media que todavía persistía en el Sur de Chile (Diálogos 63).

El propio Parra aclara un punto importante sobre este encuentro con las formas populares:

Bueno, en las primeras etapas no queda otra cosa que aferrarse a esas formas populares, separarlas, limpiarlas, pulirlas, hacerlas brillar. Pero a continuación se ve que estas imágenes populares corresponden en primer lugar a etapas históricas anteriores. Por eso lo que hay que hacer es buscar las correspondientes en nuestro mundo actual, que tienen que estar en alguna parte: están en la conversación habitual.

De esa manera se llega al lenguaje hablado. Uno anda buscando formas modernas que tengan la misma legitimidad que las formas de la poesía popular. Pero la poesía popular es una poesía ya de museo. No puede uno quedarse allí sin falsificarse a sí mismo. Lo que hay que hacer es seguir la línea de poesía popular (Morales 96-97).

En esa línea a seguir es donde Parra encuentra una de las formas festivas más importantes del ritornelo popular: la cueca.

La cueca chilena es de origen incierto, pero lo más creíble es que provenga de la zamacueca peruana, un ritmo de la época colonial de ascendencia negra que tiene entre sus componentes la samba. El baile es una danza de seducción en el que el hombre persigue a la mujer mediante diversos modos establecidos de antemano. Uno de ellos es el pasito escobillado sobre el suelo, que posteriormente da paso al zapateado del varón, que se pavonea de punta y taco. El ritmo, la danza y la letra son festivos, por lo que se hace difícil encontrar una cueca triste. 
Mi tesis es que Parra encontró en este ritmo, especialmente en el escobillado y zapateado, una de las formas de territorializar la nueva expresión (anti) poética que perseguía. Parra zapatea la gramática poética de la poesía chilena.

El ritmo de barrer el suelo y zapatear tiene diversas significaciones metafóricas como modelos de construcción de la antipoesía. Barrer el suelo puede significar que Parra "limpia" el lenguaje poético chileno del "surrealismo de segunda mano", del "decadentismo de tercera mano", de "tablas viejas devueltas por el mar". Pero barrer puede apuntar también a la "barrida" de los "poetas padres" que efectúa el antipoeta:

Nada más, compañeros

Nosotros condenamos

-y esto sí que lo digo con respeto-

poesía de pequeño Dios

La poesía de vaca sagrada

La poesía de toro furioso (Obras 81).

Los tres poetas "barridos" y seguidamente "escobillados" aparecen nombrados en "La cueca de los poetas", con el agregado del nombre de Gabriela Mistral:

La vida que lindos

son los faisanes

la vida, que lindo

es el pavo real

Huifa, ay, ay, ay

La vida, más lindos

son los poemas

la vida, de la Gabriela Mistral

Huifa, ay, ay, ay

Pablo de Rokha es bueno

pero Vicente

vale el doble y el triple

dice la gente

Huifa, ay, ay, ay

Dice la gente, sí

no cabe duda 
que el más gallo se llama

Pablo Neruda

Huifa, ay, ay, ay

corre que te agarra

Nicanor Parra (Obras 120).

Violeta Parra grabó en 1966 esta cueca, que a pesar de ello se mantuvo bastante desconocida para los lectores del antipoeta. No deja de ser interesante este dato porque a la luz de lo que he dicho "La cueca de los poetas" puede y debe ser considerada como una matriz expresiva o un modelo que contiene un germen, un "rizo enunciativo", que Parra desplegará en su obra posterior a Versos de salón.

Al leer "La cueca de los poetas" como un modelo enunciativo que se desarrollará ampliamente en La cueca larga, y de un modo más restringido en Versos de salón, Obra gruesa, Artefactos ("zapateo" puro) y Discurso de sobremesa, destaco fundamentalmente el "ritmo" del baile.

Se objetará inmediatamente que la música no es un lenguaje, en su sentido estricto, en cuanto los componentes del sonido no son rasgos pertinentes de la lengua y porque la distinción lengua-palabra deja fuera del lenguaje cualquier tipo de variables referidas a la expresión o a la enunciación, pero nadie podría discutir que la letra de "La cueca de los poetas" es arrastrada por un ritmo musical que dirige la fonética, la prosodia en otra dirección a la conferida por las oposiciones enunciado-enunciación, gramma-phoné, etc.

Es verdad que en la cueca de Parra está por un lado la letra y por otro la música que le colocó posteriormente Violeta Parra, pero evidentemente el antipoeta al escribir sometió la prosodia al compás de la cueca y trabajó la fonética según ese mismo modelo rítmico.

El estribillo "Huifa, ay, ay, ay" es el eje en torno al cual se produce el devenir musical de todas las variables. Más que leerlo al estribillo obliga a escucharlo. Y si lo hacemos, él nos arrastra como ritornelo a ese inmenso canto del pueblo, del que hacía mención. Nos sintoniza con una etnia, con un territorio festivo, irónicamente festivo, ese territorio del sur profundo, según lo anotaba Edwards.

Sobre el agenciamiento con el ritornelo popular, Parra construye una (anti)poética cuyo primer ejercicio o esbozo ("rizo") enunciativo está en la primera estrofa de la cueca.

En ella aparece el lugar de la enunciación que adoptará el sujeto: el de la ironía, el humor, "el desenfado, la gracia... la simpatía juguetona", ya 
anotados por Carrasco (20). Claramente la hermosura, la "lindura", de los faisanes y el pavo real es pura externalidad frente a la verdadera belleza: la de los poemas de Gabriela Mistral. El término de comparación evidencia que las aves son metáforas de otros poetas revestidos de brillantes plumas que practican una poesía retórica (modernista) que el antipoeta va a condenar y a rechazar. Parra ha hablado varias veces de este tipo de poesía que en su aguda y peculiar nomenclatura llama la "poesía de los griegos". Una escritura solemne que busca deslumbrar y persigue la belleza de la metafísica. Es el mundo griego de las analogías y de las correspondencias en el que el poema es un espejo que duplica las armonías del mundo. A propósito de ello, me parece conveniente recordar una célebre frase de Borges que afirma que todos los hombres nacen aristotélicos o platónicos. Los primeros creen en las ideas generales; los segundos, en que las ideas son realidades. Neruda es un poeta platónico, Huidobro es aristotélico. Pero los dos son lindos faisanes que se "pavonean" con los tropos literarios al uso que la antipoesía va a expulsar. La desnudez y sequedad de los poemas mistralianos le parecen a Parra más adecuados, aunque sigue empleando el ambiguo calificativo de "lindo". Este varía grandemente según el contexto. En el ámbito popular en que se mueve "La cueca de los poetas" tiene un matiz presuntuoso, por ejemplo (Ven, lindo, por favor), o de censura (linda la que hiciste), o de admiración (linda mujer). Hablar de poemas lindos en el repertorio oral del pueblo pareciera privilegiar el último significado, pero en el campo de la escritura antipoética apunta también al carácter presuntuoso - propio de los poetas aristotélicos y platónicos.

La tercera estrofa se sitúa en el mismo rizo enunciativo ambiguo e irónico. Sin abandonar los términos propios del ritornelo popular, se califica a Pablo de Rokha de "bueno". ¿Bueno como poeta? ¿Bueno como persona? Y de Huidobro se escribe que "vale" el doble y el triple. ¿Es su poesía que vale tanto? ¿O hay que tener mucho dinero para comprar a Vicente?

Repárese que todos estos contenidos ambiguos son embargados por el festivo estribillo que funciona como un zapateo que trastorna los significados y los mueve hacia un gran ritornelo popular.

En realidad, el estribillo desterritorializa todos los significados (lindura, faisanes, pavos reales, Mistral) para reterritorializarlos en un grito libre y alegre: Huifa, ay, ay, ay.

Desterritorializar el ritornelo significa producir otro de "segundo grado" (Deleuze y Guattari 352) que en Parra ya no está en la relación con lo natal, lo originario, o el centro-sur del país, sino con nuevas fuerzas -las antipoéticas- 
que van a hacer huir las formas líricas modernistas, la "poesía griega". Ellas escapan perseguidas por los huifa, ay, ay, ay.

"La cueca de los poetas" que comienza con una medición de los antecesores de Parra va a finalizar, entonces, con la necesidad de la huida, aun del más "gallo" de los poetas padres: Pablo Neruda.

Ciertamente es cómico imaginar a Neruda corriendo, perseguido por los agarrones de Parra y por los gritos del huifa, ay, ay, ay.

Avanzando en esta línea, aparte de los gritos y huidas, es evidente que Parra juega con el sentido fundamental de la cueca, que según consenso general, es una danza que trata de seducir a una mujer (la "china").

Si lo pensamos bien, la antipoesía no tiene otra finalidad mayor que "seducir" al lector. Los círculos y las diagonales gramaticales que efectúa la escritura de Parra no solamente hacen reír, como opina la crítica, sino que centralmente pretenden seducir. Parra baila con la poesía chilena, le echa el pañuelo al cuello, la atrae y la suelta transformada en otra, como si le pasara lija:
Esa dama que baila
Se me figura
Que le pasaron lija
Por la cintura (Obras 120).

Evidentemente, la seducción a través del escobilleo y zapateo significa un alarde que hace el sujeto, un "pavoneo" destinado a lucirse. Quien no luce difícilmente seduce. Parra no se escapa a la regla. Solo que su baile es una serie de acercamientos y retiros en que va y viene, mientras el de Neruda, en Veinte poemas, se realiza en el entrelazamiento con la pareja. En tanto en Mistral bailar es tomarse las manos y danzar, conseguir un enlazamiento: "Dame la mano y danzaremos" (205).

Imagínense que si en pleno bolero y danza gritáramos: Huifa, ay, ay, ay. Tal es el trastorno inesperado que produce la antipoesía en la lírica chilena de la modernidad.

Vuelvo a replantear en esta parte que se acerca el final de la comunicación, la objeción de que la música no es un lenguaje, lo que significa concretamente que en el caso de Neruda, Parra, y lateralmente Mistral, solamente podría trabajarse con bloques de contenidos expresados en las letras del bolero y de la cueca (y eventualmente en las rondas), buscando la relación con los significados de los textos poéticos, despreocupándose de las formas de expresión. 
Pero la tesis expuesta no trabaja con estas distinciones. Ella opera con las variaciones continuas que Neruda y Parra hacen en los elementos comunes de la lengua. Creo que los poetas desterritorializan las invariantes gramaticales, más Parra que Neruda, para poner en movimiento la lengua. Crean una suerte de diagonales y transversales sintácticas y fónicas que descentralizan la lengua terminando con las distinciones entre la voz, la palabra, la lengua y la música. Variación continua inmanente que desestabiliza la sincronía y la diacronía para devenir, asincronía. Mejor dicho, cromatismo de la lengua. Ello significa estar a favor de una lengua poética cromática, lo que implica a estos autores en múltiples procedimientos de variación de las constantes, entre las cuales se destacan los intervalos fónicos y las velocidades. Los versos de Veinte poemas se construyen mediante intervalos prolongados y velocidades lentas: "Puedo escribir los versos más tristes esta noche". El modelo de Parra es de intervalo corto y velocidad loca: "Huifa, ay, ay, ay". Aquí estoy hablando de ritmo, timbre, incluso de "tesitura" de la lengua poética con lo cual elimino su distinción con la voz. Puedo hablar, entonces, de los susurros, quejas, gemidos que emanan de los Veinte poemas y de los gritos, exclamaciones, interjecciones que provienen de la antipoesía. Al trabajar con la fusión, se une en un mismo espacio los contenidos con las formas de expresión, la enunciación con el enunciado. La fusión de los contrarios es la que permite hablar de "tesitura" en relación al lenguaje. Y en los dos significados de la palabra: actitud del ánimo y altura propia de la voz. En los Veinte poemas la tesitura es melancólica y la altura de la voz mínima, algo así como ronca. En "La cueca de los poetas" ("rizo" en la antipoesía) el ánimo es festivo y la altura, semiaguda.

Para explicar mejor lo anterior, debo decir que al hablar de lengua no estoy pensando en una lengua colectiva y constante, opuesta a actos de palabras individuales y variables. Mi planteamiento se opone al de la lingüística que considera la lengua como un sistema o "máquina abstracta definida por las constantes". Pero esta "máquina" es virtual-real sin reglas obligatorias, como si en cada utilizamiento de la lengua estuviesen en juego las reglas. De ahí la importancia de los agenciamientos concretos de enunciación. La máquina siempre tiene un nombre propio: la poesía amorosa de Pablo Neruda, la antipoesía de Nicanor Parra. El agenciamiento, por el contrario, siempre es colectivo: el imaginario amoroso latinoamericano, el imaginario popular chileno. 
Ni primacía de un individuo ni de un concreto colectivo. Fusión absoluta de ambos términos. En la literatura, la máquina abstracta de la lengua es el diagrama de un agenciamiento de enunciación.

Máquina abstracta, agenciamiento

Corre que te lleva el viento.

Huifa, ay, ay, ay.

\section{BIBLIOGRAFÍA}

Carrasco, Iván. Para leer a Nicanor Parra. Santiago: Ediciones Universidad Nacional Andrés Bello, 1999.

Deleuze, Gilles. Crítica y Clínica. Barcelona: Anagrama, 1996, pp: 9-11.

Deleuze, Gilles y Felix Guattari. Mil mesetas. Capitalismo y esquizofrenia. Valencia: Pretextos, 1997.

Edwards, Jorge. Diálogos en un tejado. Barcelona: Tusquets, 2003

La otra casa. Ensayo sobre escritores chilenos. Santiago: Ediciones Universidad Diego Portales, 2006.

Mistral, Gabriela. Antología. Santiago de Chile: Editorial Zig-Zag, 1947.

Morales, Leonidas. Conversaciones con Nicanor Parra. Santiago: Editorial Universitaria, 1991.

Neruda, Pablo. Veinte poemas. Santiago de Chile: Editorial Planeta, 1998.

Parra, Nicanor. “Conversaciones con Jaime Quezada y Mario Rodríguez”. Las escrituras tienen la palabra. Santiago: Instituto Chileno Norteamericano, 1996.

Obras completas \& algo [más]. Tomo I. Barcelona: Galaxia Gutenberg, 2006. 